CASE 339._. On Nov. 23rd, 1898, I was asked by my friend Mr. R.B. Morris of Church Stretton, then resident at Urmston, to see with him a very emaciated child, aged six years, regarding whom the following history was given. On the 8th she had begun to vomit and had complained of epigastric pain. This condition had continued until the 12 th when improvement set in, and she had been allowed to get up on the $18 \mathrm{th}$. On the 20 th the condition had become much worse, the vomiting had returned and was much more frequent, the abdomen had begun to distend, and the pain had become localised and severe in the left hypochondrium. This had continued and had increased until our visit together on the 23rd. The child was in a small tenement house but was too ill to be moved. I was anxious to have her for operation in the Trendelenburg position. of course, no tahle giving this position was to be had and it was rather late at night. A stout kitchen table was obtained and upon it an equally stout kitchen chair was placed reversed so that the edge of the seat and the top of the back touched the table top. The two were securely bound together by ropes. A pillow was placed over the back of the chair, which sloped upwards at an angle of $40^{\circ}$. Upon this the child was laid when anæsthetised, the head resting on a pillow on the table, the knees and legs being secured to the legs of the chair. Abdominal section was done and a band was found exactly at the spot to which the child had persistently referred her pain; this was divided and remored and the abdomen was re-closed. A loop of small intestine which had been compressed by this band was released by its division and the child recovered absolutely, convalescence being somewhat delayed by a tendency on the part of the patient to get her fingers in the wound, this necessitating the arms being kept bound to the side of the bed.

CASE 526 - The patient, a female, aged 19 years, was admitted on March 23rd, 1903. She had suffered for years from dyspepsia, and she said that for six weeks previously to admission she had vomited everything she had taken. She had become much worse during the last fortnight. The last stool had been passed on March 12th. She complained of a "band-like" pain in the epigastrium. The abdomen was supple, was not distended, and contained no palpable mass. An enema brought away a small amount of fæcal material.

The stomach having been emptied by a syphon the abdomen was opened. The small intestine was found to be collapsed and the mesenteric veins were swollen and dark. At the hepatic flexure the whole small intestine with the ascending colon, which was quite free and unattached up to this point, were twisted upon the flexure as an axis two or three times. This volvulus was untwisted and the cæcum was fixed down by suture to the right iliac fossa, but the patient died the same night.

CASE 563.- The patient, a female, aged 32 years, was sent to hospital by Dr. T. B. Riddall of Longsight on Nov. 27th, 19j3. This was a case of muco-colitis treated by Weir's method of irrigation through the appendix, which was fixed in the abdominal wall, opened, and utilised as a channel by which the cæcum might be reached directly. The result was sufficient to encourage repetition in another case suffering from this otherwise intractable malady. It was noteworthy that at no time during the three months that the appendix remained patent was there any escape of fæces or flatus from this opening.

CASE 576 - On Sept. 5th, 1903, I was asked by my friend Mr. S. H. Mason of Moss Side to see with him a woman who had had two miscarriages, the last one 14 days previously. From this she harl apparently perfectly recovered and was to have risen from bed when she was suddenly taken ill on Sept. 3rd, the fourteenth day, with vomiting and absolute obstruction. The vomit became brown and grumous looking on the morning of the 5 th and she was at once transferred to a surgical home.

Abdominal section was performed and a coil of small intestine was found adherent for two inches deep down in the pouch of Douglas. The loop was freed and the abdomen was closer. 12 months later she was safely delivered of a full-term child and she remains in perfect health.

The symptom: and signs of ectopic pregnancy are usually clear enough and can scarcely be mistaken by those who are accustomed to them, but they completely misled me in the following case.

CASE 586.-On Feb. 2nd, 1904, I was asked by my friend Dr. Riddall to see with him and his partner, Mr. B. W. Csnway. a young woman who had been married for three months. There had been amenorrhoea for 11 weeks, with slight brownish bloody discharge for three days. There had been some pain in the left iliac fossa. On examination with the finger over the vagina and bimanually a double vagina was recognised, with double cervices. The uterus itself, however, appeared to be single and on its left side, and distinct from it, there was a small soft and tender mass which was diagnosed as a probable ectopic pregnancy. Abdominal section, however, showed a double uterus with a pregnancy on the left side, which a few days later aborted.

I have not attempted to compress into the limits of one paper a complete account of all the work suggested by the title but enough has perhaps, been said to show some of the changes which have taken place in abdominal surgery during the past 20 years and the effect of asepticity in rendering possible work which previously would have been considered impracticable.

Manchester.

\section{A CASE OF BLACKWATER FEVER OCCURRING IN THE NORTH OF IRELAND AND TREATED WITH QUININE.}

\section{BY ROBERT MOWBRAY, M.D.R.U.I.}

I REPORT this case to show that a medical man, no matter where he resides, may be called suddenly to a case of black. water fever and to assist in removing a doubt which still appears to exist as to its treatment.

The patient, a joung man engaged in constructing the Cape to Cairo Railway about and north of Victoria Falls, got his first malarial attack at the latter end of Februars, 1904, while travelling in a bullock wagon from the railhead to the Falls. He had never previously taken quinine. He had attacks off and on till the middle of July and did not taike quinine systematically as he said that it gave him pain in the back. He continued fairly free from July to October when attacks came on again and continued till February of this year when he was invalided home. He had attacks during the first week of the voyage, from which time he was free till nearly two weeks after landing in this country. About March 4th of this year he began to have attacks of ague every evening, increasing in severity till the 9 th when blackwater fever for the first time developed. I was called urgently at 7 P.M. ; he had had a severe rigor, was vomiting incessantly, and was passing urine like blood. His axillary temperature was $106.5^{\circ} \mathrm{F}$. Never having met a case belore I was in doubt as to treatment but upon the authority of published cass $\mathrm{s}$ I made up my mind that quinine given hypodermically was the right course. I gave 18 grains at once and ten grains three times a day for five days and twice a day for two following days. The patient was much better on the second day. His temperature was $102^{\circ}$ and his urine was less highly coloured, but vomiting and thirst kept up until the third day, when he became fairly comfortable. A week after the attack his urine was quite clear and gave no deposit on boiling, but his temperature never sank below $100^{\circ}$ in the axilla. Just one week from the first attack he had a relapse in the middle of the night; his temperature was $105.5^{\circ}$, he was delirious, vomiting, and passing urine like blood. I now blamed myself for having lessened the quantity of quinine given during the last few days and determined to push it in future till, if possible, the last germ of the brood was killed. I gave 15 grains at once and 12 grains three times a day for a week. The patient rapidly improved and in a few days he was free from the black water and other distressing symptoms. At the end of the second week from the first attack, being afraid. lest I should poison my patient with quinine, I sought information in the higbest quarter as to how long it was aafe or desirable to continue such doses. My authority, after having had the advantage of talking over the telephone with one whose name is a houselsold word in malarial literature, informed me that the quinine should at once be stopped and that it should not he given at all in blackwater fever. Being still in doubt I wrote to a professor of tropical medicine and he said that my treatment was quite right and that the quinine in reduced doses should be given for the next few rnonths. After quinine had been given for 20 dajs nature took the case into 
her own hands. A violent attack of acute dyspepsia, which a single dose of quinine seemed to aggravate, came on and continued for two weeks by which time the patient was greatly exhausted and emaciated. After this he began to recover, at first slowly then rapidly gaining strength till five months a ter the first attack at home, he is quite well and strong. Latterly, he has resumed quinine in small doses but intends in future to keep out of the way of infection. About 60 injections were given each in two drachms of fluid by an ordinary serum syringe; both the syringe and solution having been previously boiled no puncture became septic. Anæsthesia lasting for weeks was caused by the quinine in the neighbourhood of the punctures.

Castlederg, co. Tyrone.

\section{THE TECHNIQUE OF THE EXAMINATION OF SPUTUM FOR TUBERCLE BACILLI FULLY DESCRIBED.}

BY CHARLES GASKELL HIGGINSON, M.A., L.R.O.P. LOND., IATE ASSISTANT MEDICAI SUPERINTENDENT, CROOKSBURT OPEN-AIR
SANATORIUM.

THE examination of sputam for the tubercle bacillus is not dificult to do well if the observer has been well taught and has a good microscope; but if these conditions be absent the results are most unsatisfactory. I regret to say that in my judgment none of the many text-books that $I$ have consulted (except Dr. Charles H. Melland's "Clinical Manual ") goes into sufficient detail on this point. Therefore I venture to support Dr. Melland's attempt at detailed exposition and proceed to describe with even more detail my own practice as I learned it from Mr. Roland A. Stevenson at Pinewood, near Wokingham. I take off the cover from the little glazed saucer in which the fresh sputum lies; then, with a pair of sharp-pointed forceps, I make a sudden snatch at the most purulent part of the sputum. Thus I get at the end of the forceps a tiny bead of sticky sputum. I then take a bright, clean, glass slide, rub it over with washleather, and write on its lower end with one of the pencils made by Faber for marking glass or earthenware the name or number of the patient and the date of examination. On this slide with the forceps I thoroughly tease out the tiny bead of sputum, so that in the centre of the slide there is the thinnest possible film of sputum spread over a circle of about half an inch in diameter. The points of the forceps are then heated red-hot in the flame, plunged into a cup of cold water, and dried on a clean cloth in readiness for future use. The film is often seen to be quite dry, but, if not so, I hold the slide with a thumb and forefinger at each end and pass it once or oftener, film upwards, over the flame of a spirit lamp, taking care by touching the bottom of the slide with a finger, that it shall not be made any hotter than the finger can bear. Having done this until there is no more moisture to be seen in the film, I lay the slide, film upwards, upon a flat surface. I then take in a pipette a few drops of carbol-fuchsin solution and drop them on to the film so that it is just covered, the solution consisting of the following ingredients : fuchsin, one gramme; absolute alcohol, 15 cubic centimetres ; and carbolic acid solution ( 5 per cent.) 85 cubic centimetres. I then pass the slide, film upwards, through the flame of the spirit lamp as before; at the first passage the lamp deposits a watery mist on the cold slide; at the second or third passage this vanishes and at times the drops of carbolfuch-in solution can be seen to send up from the slide a little cloud of water vapour, though it does not and must not boil; the finger, touching the slide where it has been most expo-ed to the heat of the flame, ought to feel the slide to be about as hot as is comfortably bearable. Then the slide should be laid on a flat place, say across a glass trough of about the size of a common pen tray, such as is used to lay pipettes in. After about seven minutes the carbol fuchsin has done its work and stained the film a bright crimson. Then I take the slide to a white basin and turn on a tap of cold water with a narrow orifice on to which has been fitted 18 inches of indiarubber tubing of about the calibre of the tube of a Higginson syringe. The water should flow in a gentle stream exactly like the stream that is obtained when one of those syringes is used as a syphon; the crimson stain is then washed off in this running stream till no more pinkness remains in the water that runs off the slide. I then take one of Baird and Tatlock's glass slide-baths, each of which is about four inches long, one and a half inches broad, and four inches deep, and holds eight slides upright, each in a separate groove, and fill it two thirds full of a 25 per cent. aqueous solution of strong sulphuric acid. Into this bath I put the slide, inscription upwards, so that the film is covered. The film should be decolourised so much that when the slide has again been washed under the stream there shall appear agrinst the white background of the basin only the very faintest rose tint. This usually happens after about a minute's immersion in the sulphuric acid solution; but if, after washing with the stream from the rubber piping, a deeper tint than this is seen, the slide must be immersed again in the acid solution. On the second immersion the decolourisation proceeds with surprising rapidity, so that the slide should be washed and re-examined in ten seconds. After the slide has been washed under the tap much of the colour of the films commonly returns which the acid bath had temporarily quite removed. Then the slide with the faint rosy film is immersed in another similar slide-bath containing a saturated aqueous solution of methylene blue. (I venture to disapprove of the practice of trying to decolourise and to counterstain simultaneously by the use of a mixture of sulphuric acid and methylene blue.) In about three minutes the slide is taken out and washed under the stream from the tap. The film is then seen to be of a bright blue colour and slide is laid flat on the glass trough. The acid solution and the methylene blue solution are then poured back into their bottles and they may be used perhaps 50 times again. The slide is then dried with a clotb, the film being untouched, and the drying is completed for the slide and the film by passing the slide over the spirit lamp as previously described; or a hot air bath may be used by heating a metal slide rack on wire gauze on a tripod over a spirit lamp. A drop of cedar oil is placed on the film and the microscope is brought out. The microscope is fitted with an Abbe condenser so that the light may be concentrated on the film; it has also three object lenses, of one inch, one-sixth of an inch, and one-twelfth of an inch respectively, all of which are fixed on a nose-piece and can by mere rotation, without any screwing and unscrewing, be adjusted in tarn to the central axis of the barrel and the eye-piece. The blind is drawn down and an electric light is turned on, fitted with a paraboloid reflector so as to illuminate the microscope's mirror. The slide is then brought on to the stage, which is itself moveable by a couple of coarse adjustment screws, along an ordinate and an abscissa at right angles to each other, up and down and from side to side. It is then focussed by the one inch lens. A bundle of blue fibres should be selected and placed in the centre of the field. Then the one-twelfth inch lens should be switched on and by the coarse adjustment should be gently lowered, till the oil seems to rise and touch the lens. The lens is then not near enough to the slide for clear vision, and we look down the eye-piece, while with the fine adjustment we gently lower the lens till the blue fibres are focussed. The Abbé condenser should be brought close up to the slide so as to illuminate it as brightly as possible. Amidst the blue fibres and cells are seen little pink rods, some straight, most slightly curved, each about five times as long as it is broad, often two together, often many in a clump, each in appearance from one-eighth to one-sixth of an inch long. These are the tubercle bacilli, which, once stained by the carbol fuchsin, are not, as the other cells are, decolourised by the sulphuric acid nor counterstained by the methylene blue. Before I put the microscope away I wipe off the cedar oil from the lens with a silk handkerchief. If the slide is to be kept the film should be dried with blotting-paper and mounted at once in Canada balsam. If the process of counterstaining by the methylene blue be omitter, the bacilli are seen merely stained a deep crimson in a field of a faint rose pink. The two methods are perhaps equally good and I habitually use both for every specimen; on the pink slides there are usually more bacilli seen, but the blue counterstain affords the more striking demonstration. The crimson bacilli ought to stand out against the blue background almost as clearly as they are represented in the pictures of Bury's "Clinical Medicine" or Hutchinson and Rainy's "Clinical Methods."

In my experience the search for the bacilli in the sputum of consumptive patients is commonly quick, sure, and easy if the one-twelfth inch lens be used, with the oil immersion ; if 